\title{
MONITORING LANDSLIDES IN THE MUSSOORIE REGION, UTTARAKHAND USING MULTI-TEMPORAL SAR INTERFEROMETRY WITH SENTINEL-1 IMAGES
}

\author{
A. B. $\operatorname{Narayan}^{1}$, A. Tiwari ${ }^{1, *}$, M. Devara ${ }^{2}$, R. Dwivedi ${ }^{2}$, O. Dikshit ${ }^{1}$ \\ ${ }^{1}$ Indian Institute of Technology, Civil Engineering - (atiwari, avadhbn, onkar)@iitk.ac.in \\ ${ }^{2}$ Motilal Nehru National Institute of Technology, GIS Cell- (rgi1703, ramjid)@mnnit.ac.in
}

Commission V, SS: Disaster Monitoring, Damage Assessment and Risk Reduction

KEY WORDS: Landslide monitoring, geodetic techniques, LiDAR, GNSS network adjustment

\begin{abstract}
:
Occurrence of landslide events are common in the lesser Himalayan region which lie in a tectonically active zone with unstable slopes. The Mussoorie region is situated in the lesser Himalayas and is one of most visited tourist sites of the Uttarakhand state. The region is facing social and economic crisis due to the damage caused by multiple landslide events, which requires continuous monitoring for better planning and rescue operations. This study shows the time series analysis of landslide events occurring in the Mussoorie region using the Persistent Scatterer Interferometry (PSI) technique on Sentinel-1 synthetic aperture radar (SAR) images. The processing steps required to process the Sentinel-1 data stacks using both differential SAR interferometry (DInSAR) and PSI are presented. 13 Sentinel-1A C-band interferometric wide swath (IW) images covering a time period of one year are used for PSI processing, resulting in the generation of 12 differential interferograms. The PSI approach extracted 5593 measurement points in the study area. The one dimensional line of sight (1D LOS) time series displacement estimates obtained from PSI processing show a maximum velocity of $55.7 \mathrm{~mm}$ year $^{-1}$ in the radar line of sight (LOS) direction, indicating subsidence. The displacement map further used to characterize the landslide susceptible zones show higher displacement magnitude for areas near Jabarkhet, Bhataghat, Bansagad and Raipur range. Use of more Sentinel-1 images and better DInSAR processing algorithms can improve the displacement estimation and pattern detection.
\end{abstract}

\section{INTRODUCTION}

\subsection{Landslide detection and analysis}

The Himalayan region is mostly affected by deformation events primarily comprising landslides, subsidence and earthquakes. Landslides in these regions mostly occur due to rainfall during the monsoon period [7]. A series of such events can cause loss of life and property, making severe impact on socio-economic factors in cities and towns with greater population density. The areas prone to these events require near real time monitoring using modern surveying techniques in order to facilitate security and remedial measures. Over the last decade, synthetic aperture radar interferometry (InSAR) has been successfully exploited to measure 1 dimensional line of sight (1D LOS) earth surface movement by generating phase difference images known as interferograms [4]. Surface displacement over a time series can be estimated using multi-temporal SAR interferometry (MTInSAR) techniques e.g. persistent scatterer interferometry (PSI), small baseline subset approach (SBAS), SqueeSAR, etc.as seen in [1] [3] [4][6]. MT-InSAR algorithms require selection of a set of SAR images with same relative orbit having less spatial and temporal decorrelation. Limitations related to spatial and temporal decorrelation mostly occur in non-urban areas, which result in loss of interferometric coherence causing extraction of less number of measurement pixels from the interferograms [6] [9].

The Sentinel-1 (S-1) mission launched by the European space agency (ESA) provides interferometric wide swath (IW) SAR images with a revisit period of 12 days, spatial coverage of $\sim 250$ $\mathrm{km}$ and a spatial resolution of $20 \times 5 \mathrm{~m}$ in range and azimuth respectively. These images are acquired using the terrain observation by progressive scans (TOPS) mode, causing azimuth resolution to be constant over the entire swath [5] [8]. The 12 day revisit along with the employment of a large orbital tube for data acquisition reduces spatial and temporal decorrelation problems [10]. S-1 TOPS images have been with using InSAR algorithms to study the effect of subsidence in Mexico City by [8] and to understand the dynamics of the Fogo volcanic eruptions by [5]. These images can be processed using the above mentioned MTInSAR algorithms to generate 1D LOS velocity maps. The displacement maps can then be used to estimate surface movement over a time series, thereby helping in interpretation of the movement pattern.

\subsection{Objective}

This research work focusses on the application of PSI approach on S-1 TOPS images to study the effect of landslides in the Mussoorie region, Uttarakhand and to find out the prominent landslide susceptible zones over the period of study.

\subsection{Study area and satellite datasets}

The Mussoorie region lies in the Uttarakhand state, near to Dehradun city. The region is well known to tourists, with hill ranges situated east-west parallel to the valleys of Dehradun and Siwaliks. Figure 1 shows the study area. The area involves hill ranges, populous areas involving villages, the Mall road, and the Mussoorie Lake. The city has a population of nearly $\sim 35000$, varying with time as more people arrive from summer to autumn season [7]. Local geological conditions and rainfall are prime causes of landslides in this region. Large number of tourists visiting the area along with people staying in villages and towns emphasizes monitoring of the site for deformation events. $13 \mathrm{~S}-1$ TOPS images acquired for a period of one year are used in this study. More details on the dataset used can be seen in Table 1 . The next section will provide description of the methodology followed in this study, followed by results and conclusion. 


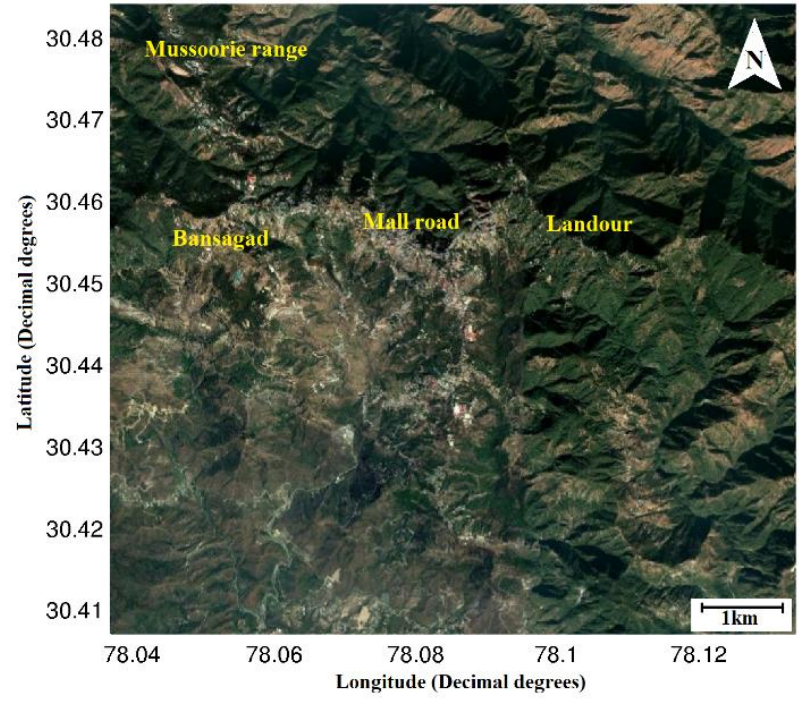

Figure 1. Google earth view of the Mussoorie region

Table 1. Sentinel-1 TOPS dataset for the Mussoorie region. Image acquired on 18 April 2016 is taken as the master image.

\begin{tabular}{|c|r|c|}
\hline $\begin{array}{c}\text { Acquisition } \\
\text { date }\end{array}$ & \multicolumn{1}{c|}{$\begin{array}{c}\text { Bperp } \\
(\mathrm{m})\end{array}$} & $\begin{array}{c}\text { Btemp } \\
\text { (days) }\end{array}$ \\
\hline 26 Nov 2015 & 169.81 & 120 \\
\hline 20 Dec 2015 & 93.26 & 96 \\
\hline 13 Jan 2016 & 111.51 & 72 \\
\hline 06 Feb 2016 & 115.60 & 48 \\
\hline 01 Mar 2016 & 9.17 & 24 \\
\hline 18 Apr 2016 & 0.00 & 0.00 \\
\hline 12 May 2016 & 54.60 & 24 \\
\hline 05 Jun 2016 & 93.26 & 48 \\
\hline 29 Jun 2016 & 19.50 & 72 \\
\hline 23 Jul 2016 & 102.72 & 96 \\
\hline 16 Aug 2016 & 70.06 & 120 \\
\hline 09 Sep 2016 & 35.89 & 144 \\
\hline 03 Oct 2016 & 102.38 & 168 \\
\hline
\end{tabular}

\section{METHODOLOGY}

In this study, S-1 TOPS data is processed using PSI technique. This can be sub divided into two parts, i.e. generation of a stack of differential interferograms and PSI processing of the differential interferograms. The former uses the Sentinels application platform (SNAP) toolbox while the latter part is processed in StaMPS environment.

\subsection{Differential interferogram stack generation}

Figure 2 shows the procedure for preparing a stack of differential interferograms. S-1 IW TOPS images comprise three sub-swaths named IW1, IW2 and IW3. Each image has to be split into one sub-swath selecting one sub-swath such that it includes the same area ground coverage for all the images. Orbital corrections are applied to remove the orbit related errors. After this, the images are stacked together, resulting in a stack of SAR images. The images can now be co-registered with respect to a master image, chosen among the set of images based on perpendicular and temporal baselines [6].These images need to be deburst to remove demarcation boundaries from the selected sub-swath. Once deburst, the geographical region of interest can be cropped from the image stack using the subset operation. The image stack is now ready for interferogram formation, which requires multiplication of a pixel with complex conjugate of the corresponding pixel in the other image. Topographic correction can be done using an external digital elevation model (DEM) e.g. SRTM on the interferograms to get a stack of differential interferograms [2] [3] [4] [6].

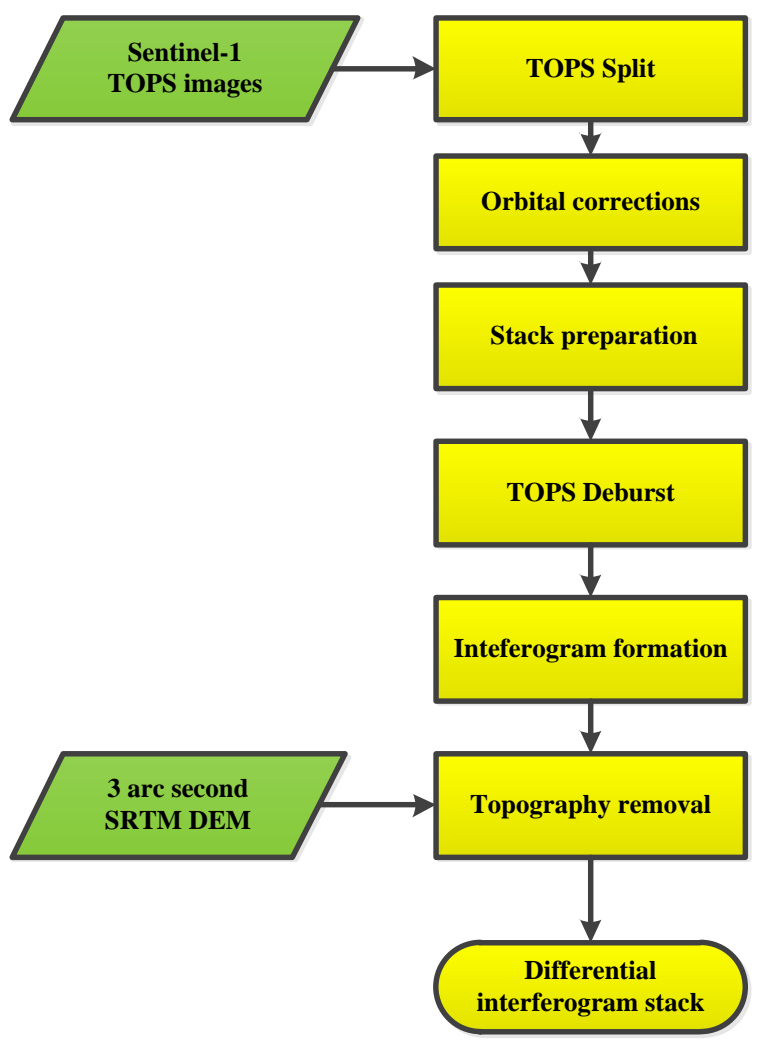

Figure 2. SNAP workflow for preparation of differential interferogram stack.

\subsection{PSI processing of S-1 TOPS differential interferograms}

The differential interferogram stack can be processed using the PSI approach in the StaMPS environment, provided that the data is converted to StaMPS compatible format. The primary PSI processing steps are reliable PS selection, phase unwrapping and displacement estimation [6] [10]. Figure 2 shows the PSI processing steps. For selecting PS pixels, a set of candidate PS pixels are initially identified based on the pixel amplitude dispersion index, i.e. the ratio of standard deviation and mean of the pixels in a time series. The pixels which pass this test are tested for phase stability using their time series phase deviation. 
Pixels which are selected in this test are selected as PS pixels. The phase of these pixels contain components from atmospheric error $\Delta \phi_{\text {atm }, x, i}$, surface displacement $\Delta \phi_{\text {disp }, x, i}$, topographic error $\Delta \phi_{\text {topo }, x, i}$, noise $\Delta \phi_{\text {noise } x, i}$ and earth flattening $\Delta \phi_{\text {flat }, x, i}$ as shown in equation (1), where $k$ denotes the number of unknown phase cycles required the unwrap the phase $\left\{\Delta \phi_{x, i}\right\}_{w}$ of the $i^{\text {th }}$ pixel in the $x^{\text {th }}$ interferogram and $w$ is the wrapping operator. In the next step, phase unwrapping is done to unwrap the phase of the selected PS pixels [4] [6] [10]. Once unwrapped, the unwrapped phase $\Delta \phi_{x, i}$ can be converted to 1D LOS change in range using equation (2), where $n$ is the known number of integer phase cycles, $\lambda$ is the wavelength and $\Delta R_{x, i}$ corresponds to change in range for pixel $i$ in the $x^{\text {th }}$ interferogram. The final deliverable is a 1D LOS velocity map showing time series velocity of each PS pixel over the period of study.

$$
\begin{aligned}
\begin{aligned}
\left.\Delta \phi_{x, i}\right\}_{w}= & \Delta \phi_{\text {disp }, x, i}+\Delta \phi_{\text {flat }, x, i}+\Delta \phi_{\text {atm }, x, i} \\
& +\Delta \phi_{\text {topo }, x, i}+\Delta \phi_{\text {noise }, x, i}+k .2 \pi
\end{aligned} \\
\Delta \phi_{x, i}=\frac{4 \pi}{\lambda} \Delta R_{x, i}+n \pi
\end{aligned}
$$

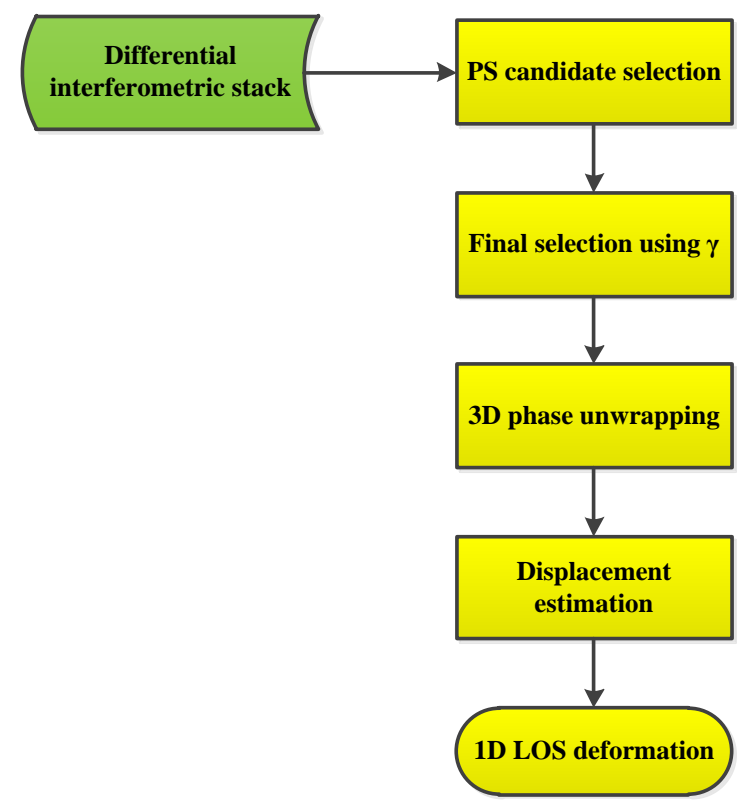

Figure 3. PSI processing chain for Sentinel-1 TOPS differential interferograms.

\section{RESULTS}

13 S-1 IW TOPS images of the Mussoorie region covering a time period of 15 months are processed using the SNAP toolbox for generating a stack of differential interferograms. One of the image (18 April 2016) is chosen as the master image. The images are first split using the S-1 TOPS split, corrected for orbital correction and then co-registered and resampled with respect to the master image, resulting in 12 geocoded, topography removed differential interferograms. For PSI analysis, the stack of differential interferograms are exported to StaMPS environment. PS candidate selection is done using an amplitude dispersion index value of 0.3 , finding 12431 PS candidates. Subsequent to this, phase standard deviation value of 0.005 is chosen, resulting in a final set of 5593 pixels. Further, 3D phase unwrapping is applied to unwrap the interferograms. Change in the unwrapped pixel phase values over the period of study are converted to change in $1 \mathrm{D}$ LOS range using equation (2).

Figure 4 shows the 1D LOS velocity map obtained for the Mussoorie region with colorbar representing average displacement rate. It is observed that the area has subsided, with cold colours in the map showing higher magnitude of subsidence, i.e. movement towards the LOS. From the velocity map, it can be seen that the area near Jabarkhet, Bhataghat, Raipur range and Bansagad show higher displacement magnitude. Areas with higher population density, i.e. the villages, the mall road and the mall show little displacement. Figure 5 shows a time series velocity for a sample measurement point in the study area showing that the point has moved downwards over the time series. More images of the study area processed in time series can provide more insights about the deformation pattern.

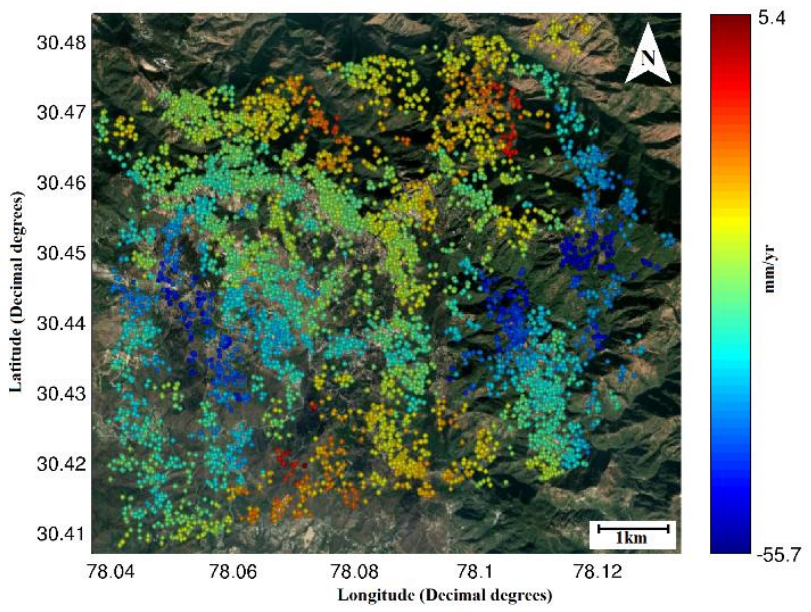

Figure 4. 1D LOS velocity plot of the Mussoorie region obtained from PSI approach. 

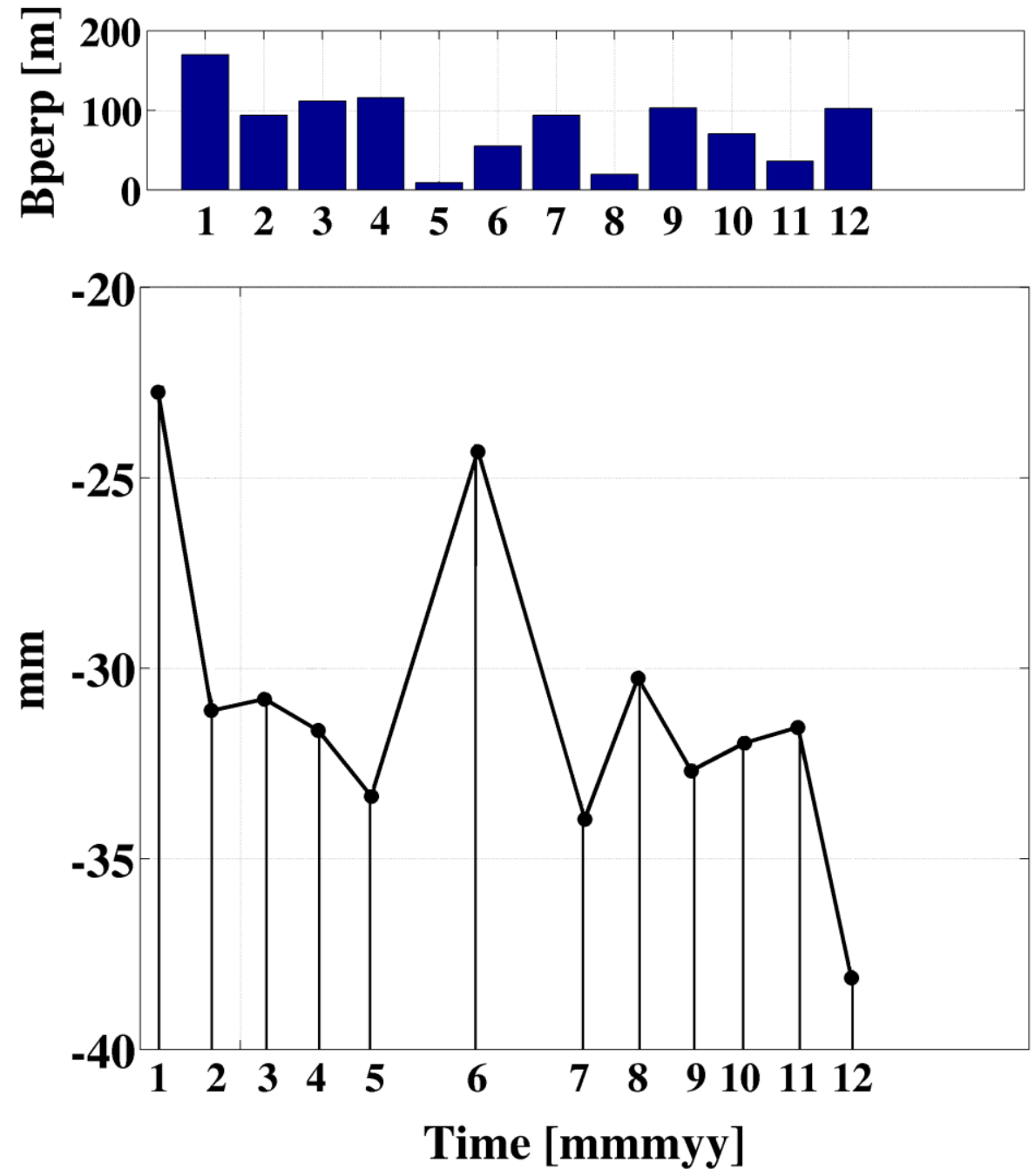

Time [mmmyy]

1. 0015-11-25

2. 0015-12-19

3. 0016-01-12

4. 0016-02-05

5. 0016-02-29

6. 0016-04-17

7. 0016-06-04

8. 0016-06-28

9. 0016-07-22

10. 0016-08-15

11. 0016-09-08

12. 0016-10-02

Figure 5. Time series velocity plot for a sample ps pixel.

\section{REFERENCES}

Aydin, C., 2014. Geodetic deformation analysis: Short lecture notes for graduate students, YTU-Geodesy Division, Istanbul.

Barbarella, M., and Fiani, M., 2013. Monitoring of large landslides by Terrestrial Laser Scanning techniques: field data collection and processing, European Journal of Remote Sensing, 46(1), 126-151.

Burkholder, E.F., 2005. Magical Least Squares - or When is one Least Squares adjustment better than another?, NMSU Department of Surveying Engineering, Las Cruces.

Caspary, W.F., Haen, W., Borutta, H., 1990. Deformation analysis by statistical methods, Technometrics, 32(1), 49-57.

Cai, J., Wang, J., Wu, J., Hu, C., Grafarend, E., Chen, J., 2008. Horizontal deformation rate analysis based on Multiepoch GNSS Measurements, Journal of Surveying Engineering-ASCE, 134 (4), 132-137.
Capilla, R.M., Berne, J.L., Martin, A., Rodrigo, R., 2016. Simulation case study of deformations and landslides using realtime GNSS precise point positioning technique, Geomatics, Natural hazards and Risk, 7 (6), 1856-1873.

Castagnetti, C, Bertacchini, C., Corsini, A., Capra, A., 2013. "Multi-sensors integrated system for landslide monitoring: critical issues in system setup and data management", European Journal of Remote Sensing, 46 (1), 104-124.

Cederholm, P., 2003. Deformation analysis using confidence ellipsoids, Survey Review, 37 (287), 31-45.

Ching, K.E., Hsieh, M.L., Johnson, K.M., Chen, K.H., Rau, R.J., Yang, M., 2011. "Modern vertical deformation rates and mountain building in Taiwan from precise leveling and continuous GPS observations, 2000-2008 “, Journal of Geophysical Research, 116, DOI: 10.1029/2011JB008242.

Denora, D., Romano, L., Cecaro, G., 2011. Terrestrial laser scanning for the Montaguto landslide (Southern Italy), Proceedings of the Second World Landslide Forum, 3-7 October 2011, Rome. 
Dorota, A., Brzezinska, G., Toth, C., Wu, T.H., Shakoor, A., 2015. Probabilistic Use of LiDAR Data to Detect and Characterize Landslides, The Ohio State University.

Dwivedi, R., Dikshit, O., 2013. A comparison of particle swarm optimization (PSO) and genetic algorithm (GA) in second order design (SOD) of GPS networks, Journal of Applied Geodesy, 7 (2).

Farolfi, G. and Ventisette, C., 2017 Strain rates in the Alpine Mediterranean region: insights from advanced techniques of data processing. GPS Solutions, 21(3), pp.1027-1036.

Fressard, M., Macquire, O., Thiery, Y., Davidson, R., Lissak, C., 2016. Multi-method characterisation of an active landslide: Case study in the Pays d'Auge plateau (Normandy, France), Geomorphology, 270, 22-39.

Fuhrmann, T., Cuenca, M.C., Knopfler, A., Van Leigen, F.J., Mayer, M., Westerhaus, M., Hanssen, R., Heck, B., 2015. Combining InSAR, Levelling and GNSS for the estimation of 3D surface displacements, Fringe 2015 Workshop', Frascati, Italy, ESA SP-731, 21-27 March, 2015.

Jaboyedoff, M., Oppikofer, T., Abellan, A., Derron, M.H., Loye, A., Metxzger, R., Pedrazzini, A., 2012. Use of LIDAR in landslide investigations: a review, Natural Hazards, 61, 5-28.

Jebur, M.N., Pradhan, B., Tehrani, M.S., 2014. Optimization of landslide conditioning factors using very high-resolution airborne laser scanning (LiDAR) data at catchment scale, Remote Sensing of Environment, 152, 150-165.

Kornejady, A., Ownegh, M., Bahremand, A., 2017. Landslide susceptibility assessment using maximum entropy model with two different data sampling methods, Catena, 152, 144-162.

Lollino, G., Pasculli, A., Sciarra, N., Baldo, M., Giordan, D., 2007. An integrated methodology based On Lidar, GNSS And Photogrammetric Surveys applied to a large Landslide in San Martino Sulla Marruccina (Central Italy), Proceedings of First North American Landslide Conference, 23.

Parida, G., and Rajan, K.S., 2017. Localized segment based processing for automatic building extraction from Lidar data, International Archives of the Photogrammetry, Remote Sensing and Spatial Information Science, 42(8), Hannover, Germany.

Qin, S., Wang, W., Song, S., 2017. "Comparative study on vertical deformation based on GPS and leveling data", Geodesy and Geodynamics, 9, 115-120.

Rawat, M.S., Uniyal, D.P., Dobhal, R., Joshi, V., Rawat, B.S., Bartwal, A., Singh, D., Aswal, A., 2015. "Study of landslide hazard zonation in Mandakini Valley, Rudraprayag district, Uttarakhand using remote sensing and GIS”, Current Science, 109 (1).

Setan, H., Singh, R., 2001. Deformation analysis of a geodetic monitoring network, Geomatica, 55(3).

Singh, V., Dwivedi, R., 2016. First-Order Design of GPS Networks Using Particle Swarm Optimization, ASCE Journal of Surveying Engineering, 142 (3).

Syahmi, M.Z., Wan Aziz, W.A., Zulkarnaini, M.A., Anuar, A., Othman, Z., 2011. The Movement Detection on the Landslide
Surface by Using Terrestrial Laser Scanning, 2011 IEEE Control and System Graduate Research Colloquium.

Teke, K., Yalkincaya, M., Konak, H., 2008. Optimization of GNSS networks for landslide areas, Fresenius Environmental Bulletin, 17(8).

Tzur, G.E., Papo, H.B., 1996. Optimization of GNSS networks by linear programming, Survey Review, 33(62), 537-545.

Wan Aziz, W.A., Syahmi, M.Z., Anuar, A., Khairul Nizam, T., 2012. Terrain Slope Analyses between Terrestrial Laser Scanner and Airborne Laser Scanning, 2012 IEEE Control and System Graduate Research Colloquium. 